\title{
REDUCCIONES, BLANDENGUES Y “EL ENJAMBRE DE INDIOS DEL CHACO”: ENTRE LAS GUERRAS COLONIALES DE FRONTERA Y LAS GUERRAS DE LA REVOLUCION EN EL NORTE SANTAFESINO ${ }^{1}$
}

\author{
Reductions, Blandengues, and "el enjambre de indios del Chaco": between the \\ colonial wars in the frontier and the revolutionary wars in the North of Santa Fe
}

\author{
Raúl O. Fradkin y Silvia M. Ratto
}

\section{Resumen}

El proceso revolucionario desarrollado en el espacio rioplatense desde 1810 desestabilizó las relaciones fronterizas entre las sociedades hispano-criollas y los grupos indígenas de la Araucanía, del área pampeano-patagónica y del Chaco. Esa situación convirtió a las parcialidades no sometidas al dominio colonial en importantes aliados de los bandos en conflicto. Esas alianzas, sin embargo, fueron muy inestables. El objetivo de este artículo es analizar el funcionamiento del dispositivo fronterizo santafesino conformado durante el siglo XVIII y desestabilizado con la crisis revolucionaria; se busca, asimismo, indagar en las características que adoptó la guerra revolucionaria en ese espacio provincial.

$<$ Guerra revolucionaria $><$ frontera $><$ blandengues $><$ indios del Chaco $>$

\begin{abstract}
The revolutionary process developed in the Rio de la Plata from 1810 destabilized the border relations between the Spanish-Creole societies and the indigenous groups of Araucania, Pampa and Patagonia and Chaco. This situation transformed the independent indians into important allies of the warring factions. These alliances, however, were very unstable. The aim of this paper is to analyze the particular defensive structure in the frontier of Northern Santa Fe and the disorganization produced by the revolutionary crisis; besides, the paper investigates the characteristics of the revolutionary war in this area.

$<$ Revolutionary Wars $><$ frontier $><$ blandengues $><$ Chaco Indians $>$

\footnotetext{
${ }^{1}$ Este trabajo forma parte de una investigación mayor realizada en el marco del PIP/CONICET, “Relaciones de poder y construcción de liderazgos locales. Gobierno, justicias y milicias en el espacio fronterizo de Buenos Aires y Santa Fe entre 1720 y 1830" (Director Darío Gabriel Barriera). Una versión anterior fue presentada en las 5tas Jornadas de la Asociación Uruguaya de Historia Económica realizadas en Montevideo entre el 23 y el 25 de noviembre de 2011.
} 


\section{Introducción}

El proceso revolucionario que sacudió al espacio rioplatense desde 1810 desestabilizó las relaciones fronterizas entre las sociedades hispano-criollas y los grupos indígenas que habitaban la Araucanía, el área pampeano-patagónica y las llanuras chaqueñas. Esa situación convirtió a diversas parcialidades no sometidas en actores decisivos de las luchas desatadas por la revolución estableciendo inestables alianzas con los bandos en pugna y con las autoridades encargadas de gobernar una sección de esas fronteras al tiempo que intensificó los conflictos entre ellas. ${ }^{2}$ La cuestión se tornó imperiosa para cada uno de los estados provinciales que estaban surgiendo de la desintegración del orden colonial a los cuales se les tornaba extremadamente dificultoso implementar una estrategia coordinada dado que los conflictos desatados entre ellos eran eficazmente aprovechados por las parcialidades indígenas.

En ese contexto, el 25 de junio de 1822, el gobernador de Santa Fe Estanislao López le escribía a su colega de Corrientes, Juan J. Blanco intentando disuadirlo de establecer una paz por separado con algunos grupos chaqueños y le advertía: “Jamás se me vino a la cabeza el pensamiento de invadir el enjambre de indios del Chaco, como dejo dicho, sino a los abipones de San Pedro, Espín y a los que llaman montaraces, que son aliados de estos mismos pueblos, que son los que practican las invasiones de su provincia y demás limítrofes; así, es inútil convidar a los abipones para arruinar a sus coligados". ${ }^{3}$ La cita permite identificar algunos de los dilemas e incertidumbres que acosaban a las nuevas entidades provinciales rioplatenses en proceso de formación al comenzar la década de 1820 y, en particular, las que surgían a la hora de definir estrategias para estabilizar sus relaciones con los grupos indígenas chaqueños tras el derrumbe del orden colonial en el espacio rioplatense. Ese “enjambre de indios del Chaco", como gráficamente lo calificaba López, estaba configurado por una variedad de grupos que mantenían laxas e inestables relaciones con las autoridades fronterizas (como los abipones de las reducciones aludidas), sostenían antiguos conflictos entre ellos (como los que habían signado la historia de abipones y mocovíes) o se mantenían persistentemente fuera de todo control (los llamados "montaraces" que también establecían alianzas o conflictos con los indios reducidos). Los mismos dilemas se habían demostrado insuperables para las autoridades coloniales pero la crisis revolucionaria los había tornado perentorios. Y, en especial, lo fueron para las autoridades de Santa Fe cuya formación como estado autónomo y la misma organización de sus fuerzas beligerantes fue inseparable de la dinámica de estas relaciones fronterizas.

El objetivo de este artículo es analizar el funcionamiento del dispositivo fronterizo santafesino conformado durante el siglo XVIII y desestabilizado con la crisis revolucionaria y sus repercusiones en el desenvolvimiento de la lucha revolucionaria. Debe considerarse que desde 1815 Santa Fe se convirtió en epicentro

\footnotetext{
${ }^{2}$ Un panorama actualizado en Ratto 2008.

${ }^{3}$ Papeles de Estanislao López, Santa Fe, Archivo General de la Provincia de Santa Fe (PEL), Vol. II, 18201822, 1977, No 371. López al gobernador de Corrientes Juan J. Blanco, Santa Fe, 25 de junio de 1822, p. $143-145$.
} 
de las confrontaciones en el Litoral y que la información disponible indica que las características del modelo defensivo fronterizo impactaron de manera directa en la composición de las fuerzas revolucionarias santafesinas. Como es sabido, durante el período tardo colonial, la defensa de los espacios fronterizos en las colonias españolas, si bien respondía a directivas generales que intentaban aligerar el peso financiero de la guerra asentando la relación interétnica con contactos pacíficos, tuvo un desarrollo dispar (Weber, 2007). Esa disparidad respondía a la que ofrecían los contextos locales. Así, en el norte del actual México fue característico el complejo misión - fuerte - presidio (Weber 2007), un esquema que se ensayó en la frontera chaqueña de la gobernación del Tucumán pero con poco éxito (Vitar 1997; Santamaría 1994; Teruel 1994). En el Río de la Plata desde la década de 1730 se intentó montar el mismo tipo de dispositivo pero mientras en la frontera bonaerense la experiencia misionera desarrollada en la década de 1740 resultó efímera y fallida, en la santafesina -a pesar de todas sus limitacioneslas reducciones adquirieron importancia central.

\section{Las peculiaridades del contexto santafesino}

La ciudad de Santa Fe de la Vera Cruz había sido fundada en 1573 por un impulso colonizador originado en Asunción que sería completado en 1580 con la segunda y definitiva fundación de Buenos Aires y en 1588 con la de San Juan de Vera de las Siete Corrientes. De este modo, el primer espacio colonial del litoral rioplatense se estructuró en torno a acotados corredores situados a la vera de los ríos Paraná y de la Plata circunscriptos por grupos indígenas que resistían su reducción. En consecuencia, hacia 1660 la ciudad de Santa Fe tuvo que ser trasladada $80 \mathrm{~km}$ al sur hasta su emplazamiento actual (Areces, 1999; Barriera, 2006).

De este modo, la experiencia histórica santafesina estuvo signada desde un comienzo y hasta fines del siglo XIX por sus inestables relaciones con los grupos indígenas chaqueños. ${ }^{4}$ Esa restricción estructural tuvo dos implicancias primordiales. Por un lado, obligó a los colonos santafesinos a volcar su interés hacia las tierras situadas en la otra banda del río Paraná, territorio que habría de convertirse durante el siglo XVIII en la principal zona proveedora de recursos agrarios de la ciudad de Santa Fe (Fradkin y Garavaglia, 2009, 87-110. Por otro, convirtió a la cercana frontera chaqueña en una prioridad absoluta para la ciudad, pero no así para las autoridades coloniales superiores lo que generó repetidos conflictos entre ellas y la elite santafesina. ${ }^{5}$

\footnotetext{
${ }^{4}$ Téngase en cuenta que el espacio controlado por la sociedad santafesina se mantuvo sin alteraciones sustanciales desde fines del siglo XVIII hasta la década de 1860, una situación francamente diferente de lo que estaba ocurriendo en las provincias vecinas como Corrientes, Entre Ríos o Buenos Aires que durante la primera mitad del siglo XIX produjeron una notable ampliación de sus fronteras agrarias.

${ }^{5}$ Santa Fe formó parte inicialmente de la jurisdicción de la Gobernación del Paraguay y desde 1618 de la Gobernación del Río de la Plata con cabecera en Buenos Aires así como de su Obispado. Mantuvo ese estatuto como Tenencia de Gobernación aun después que en 1783 las autoridades del recién organizado Virreinato el Río de la Plata pusieran en marcha el régimen de Intendencias, quedando Santa Fe incluida dentro de la jurisdicción de la Intendencia de Buenos Aires. Mantendría esta situación subordinada hasta que en 1815 proclamó su "independencia" de la capital y a costa de una dura confrontación a través de la
} 
En estas condiciones, la conformación de hinterland santafesino descansó en buena medida en las reducciones que desde las primeras décadas del siglo XVII comenzó a organizar la Compañía de Jesús en esa frontera, las cuales habrían de adquirir mayor solidez desde mediados del XVIII. Ese dispositivo fue enriquecido con la instalación de precarios fuertes desde la década de 1720 y por la formación de nuevas fuerzas militares dispuestas al efecto ante la ineficacia de las milicias para asegurar su defensa (Areces, 2002; Battcock, Gotta y Manavella 2004). Sin embargo, ese esfuerzo defensivo debió desarrollarse en medio de las restricciones impuestas por las autoridades superiores que exigían contingentes para campañas ofensivas en territorios alejados y ofrecían muy limitada colaboración para la defensa de la frontera chaqueña. Por ello, las autoridades locales se orientaron a mejorar la administración de las reducciones y, como era moneda corriente en otras zonas fronterizas, a sumar a las reducidas tropas hispano-criollas a fuerzas indígenas auxiliares (Giudicelli 2009). Pero también desarrollaron una fuerza armada propia para estos fines, los Blandengues de la Frontera de Santa Fe, una fuerza de dimensiones reducidas pero que tuvo un lugar creciente en el esquema de poder en la sociedad santafesina. Fue esta situación la que configuró a los actores locales y trazó el cuadro de tensiones que se intensificaron notablemente durante la era revolucionaria. ${ }^{6}$

\section{Los orígenes del sistema defensivo de la frontera santafesino-chaqueña}

Las compañías de Blandengues de la Frontera de Santa Fe tuvieron su origen en las que se formaron en la década de 1720 para defender la frontera chaqueña. Se trataba de una compañía de lanceros de caballería a sueldo y de servicio permanente, reclutada y comandada localmente y sostenida por el ramo de arbitrios del cabildo santafesino. Habría de convertirse en la única unidad veterana -regular- en la Gobernación de Buenos Aires fuera de las compañías de infantería de origen peninsular asentadas en las ciudades de Buenos Aires y Montevideo y era considerada como una fuerza veterana, al punto que se la denominada Compañía de Dotación. ${ }^{7}$ El servicio de esta compañía debía ser prestado en los fuertes que se organizaron para asegurar la defensa de la frontera chaqueña de Santa Fe. ${ }^{8}$ La experiencia fue exitosa pues a partir de 1752 se extendió a la frontera de Buenos Aires, a partir de 1784 fueron convertidos en unidades veteranas y desde 1797 se organizó un nuevo cuerpo para la frontera de Montevideo. ${ }^{9}$

cual iba a adquirir la condición de un estado provincial soberano.

${ }^{6}$ Hasta ahora los estudios sobre los Blandengues han estado concentrados en la frontera bonaerense pero menos atención ha merecido la experiencia santafesina: Marfany 1933; Mayo y Latrubesse 1993; Alemano y Carlón 2009.

7 Para ahondar sobre las diferenciación entre fuerzas veteranas y milicianas remitimos a Marchena Fernandez 1992.

${ }^{8}$ Actas del Cabildo de Santa Fe (ACSF) del 8 de Agosto de 1724, Tomo IX, IX f 185 a 188v 8 de Agosto de 1724, Tomo IX, IX f 182v a 185 y 31 de Agosto de 1724, Tomo IX, IX f 192 a 193

${ }^{9}$ Los cuerpos de lanceros no eran una peculiaridad rioplatense (De la Serna 2005 y Juárez Martínez 2005) pero la experiencia de los Blandengues rioplatenses se distingue por la magnitud y centralidad que cobraron entre las fuerzas veteranas disponibles a fines de la colonia. 
Pero antes que ello sucediera en el dispositivo de defensa santafesino cobró renovado impulso desde la década de 1740 la formación de las reducciones de San Javier y San Pedro de indios mocovíes y San Jerónimo de Rey de indios abipones. Estas fundaciones se lograron por medio de las paces concertadas con algunos grupos pero su contrapartida fue la tensión en otras jurisdicciones ya que los abipones y mocovíes con quienes se había establecido la paz volcaron sus ataques, robos y saqueos sobre las ciudades vecinas. ${ }^{10}$ Un elemento a destacar es que mocovíes y abipones mantenían un largo conflicto por el control de espacios y estas reducciones tenían el objetivo, además de proteger la frontera, de aligerar esos enfrentamientos. Como se verá, ninguno de los dos propósitos fue totalmente exitoso. Pero con respecto al primero es de destacar que, al menos en los pueblos de San Pedro y de San Jerónimo existían indios de pelea que ayudaban a la defensa fronteriza: en el primero, al momento de su fundación, existían 100 indios de armas y en el segundo, a fines de la década de 1770, se podían contar "500 indios de armas y algunos de ellos capacitados en el uso de armas de fuego". ${ }^{11}$

Con respecto a su sostenimiento financiero una Real Cédula de 1748 había establecido que los 30 pueblos guaraníes, además de pagar tributo, contribuyeran, a modo de diezmo, con la suma de 100 pesos por cada uno para poder sostener los nuevos pueblos que se crearan. La Real Cédula establecía que, "aunque se havia pedido el sínodo acostumbrado para su manutención no se havia conseguido y como las ciudades de las cercanías aunque interesadas en la pacificación no ayudaban en nada ni los colegios de la provincia podían hacerlo por sus atrasos...", los 3000 pesos recaudados de los pueblos guaraníes fueran ingresados a las cajas reales como se hacía con el peso del tributo "expresado con preciso destino del gasto de las nuevas conversiones que van citadas; establecimiento de pueblos que las faciliten y demás cosas concernientes a este fin". Aparentemente, la Real Cédula no se cumplió y, en la década de 1780 el Tribunal de Cuentas de Buenos Aires denunciaba que "los sínodos de los curas doctrineros de aquellas reducciones se paguen de estos fondos [de los pueblos guaraníes] y no de las cajas reales de esta capital como se ha venido verificando sin que haya tenido nunca su debido cumplimiento aquella real cedula". ${ }^{12}$ De este modo, estas reducciones debían mantenerse con recursos derivados de los pueblos guaraníes y con los que aportara el cabildo santafesino, mientras la compañía de Blandengues se mantenía con el ramo de arbitrios de ese cabildo sin que la cabecera de gobernación - y luego del Virreinato y la Intendencia - aportara recursos a la defensa de esta frontera.

\footnotetext{
${ }^{10}$ Algunos de los autores que han estudiado estas reducciones coinciden en afirmar que prácticamente desde su inicio fracasaron en el objetivo de sedentarizar y evangelizar a la población indígena y que las poblaciones nativas asentadas en ellas las utilizaban, fundamentalmente, como un espacio más de apropiación de recursos. Ver, entre otros, Djenderedjian 2001; Lucaioli 2010 y 2011; Saeger 2000; Paz 2005 y 2009. Esta función de las misiones como centros de aprovisionamiento ya había sido señalada por Langer (1994).

${ }^{11}$ Informe del administrador de pueblos, Don José Tarragona elevado al virrey en junio del año 1780, en AGN,IX, Justicia, 8, 115. "Expediente seguido de oficio sobre las hostilidades a los yndios abipones reducidos en los pueblos de las jurisdicciones de Santa Fe en las fronteras del Chaco".

${ }^{12}$ Informe del Tribunal de Cuentas, 27 de noviembre de 1780, en Ibidem.
} 
Hacia mediados del siglo XVIII, entonces, blandengues y reducciones se convirtieron en las fuerzas defensivas del norte santafesino. Pero este esquema distaba de ser exitoso para garantizar la seguridad del espacio. Los Blandengues no se limitaron a servir en la frontera norte y nuevas exigencias dificultaron su consolidación: en la década de 1750, por ejemplo, Santa Fe debió movilizar 200 hombres en la campaña contra los guaraní-misioneros insurreccionados ${ }^{13}$ y en 1762 otros 200 en la campaña contra Portugal. ${ }^{14}$ De este modo, a comienzos de 1779 la Compañía contaba solo con 48 soldados, 8 oficiales y 1 tambor y se concentraba en los fuertes de Cululú y Arroyo Pavón a una ración de 1 11/2 real por día (Cervera, 1908,554). Si se comparan estas fuerzas con la cantidad de indios de pelea que existían en los pueblos reducidos, no cabe lugar a dudas sobre la centralidad que tenían las misiones en la defensa fronteriza. Sin embargo, la dificultad por resolver los conflictos entre abipones y mocovíes provocó la desarticulación de esta fuerza.

En efecto, a fines del año 1779 un ataque de indios abipones de San Jerónimo sobre los indios mocovíes de San Pedro y San Javier motivó la realización de un sumario judicial en donde se evidenció la deficiencia de la seguridad fronteriza en el norte de la jurisdicción santafesina. ${ }^{15}$ El teniente de gobernador, Melchor de Echagüe y Andía, informaba al Virrey que los atacantes abipones habrían sido más de 400 indios de armas "de que hoy hay muchos expertos en el manejo de ellos que les permitió mi antecesor D. Juan Francisco de la Riva Herrera con dos cañoncitos a cuyo manejo hizo adiestrarlos con el fin de resguardarse de los infieles mocovíes". Según afirmaba Echagüe, el gran número de indios abipones armados llevaba a descartar la idea de lanzar una expedición militar sobre ellos y sugería el establecimiento a inmediaciones de San Jerónimo de un fuerte guarnecido "con doscientos hombres bien armados y asistidos [...] Sin asegurar esta fuerza es poner a esta ciudad expuesta al blanco de las hostilidades de los abipones y a estos pobres vecinos en la urgencia de abandonar sus haciendas haviendo de estar continuamente con las armas en las manos". ${ }^{16}$ Se plantea entonces, un tema que sería recurrente a lo largo del tiempo: ¿de dónde saldrían los fondos para hacer frente a los gastos de defensa? El Cabildo de Santa Fe proponía que el fuerte nuevo y los hombres de su dotación se pagaran "con el producido del ramo de arbitrios de aquella ciudad". ${ }^{17}$

Paralelamente, a mediados del año 1780 el administrador de los pueblos de indios, Don José Tarragona, elevaba al Cabildo un relato de la situación existente en las reducciones a su cargo. El mismo es muy claro en mostrar el nivel de decadencia en que se hallaban y, en consecuencia, la dificultad por cumplir con el objetivo de servir de barrera de ataques externos. Con respecto a los pueblos de mocovíes, los más cercanos a la ciudad de Santa Fe, se informaba que San Pedro estaba al borde de

\footnotetext{
${ }^{13}$ ACSF, 8 de Octubre de 1755, Tomo XII B, XII f 288 a f 289.

${ }^{14}$ ACSF, 24 de Diciembre de 1778, Tomo XIV B, XIV f 525 a f 526 v.

${ }^{15}$ Ver nota 10.

${ }^{16}$ Ibidem.

${ }^{17}$ Acuerdo del Cabildo, octubre de 1779, en Ibidem.
} 
su desaparición ya que “con motivo de los incesantes robos de los abipones solo han quedado 160 cabezas de ganado vacuno cimarrón que no pudo conseguir traer al corral. Los abipones no han dejado ni un caballo ni una yegua en que andar...". Tarragona expresaba su temor de que si no se garantizaba una eficaz defensa del mismo, éste sería abandonado lo que llevaría a una peligrosa indefensión de la ciudad “dejando una entrada libre a los abipones y vuelva el peligro a las frontera como era antes de la fundación del pueblo". ${ }^{18}$

A inicios de marzo de 1781 los abipones de San Jerónimo volvieron a atacar a los mocovíes de San Javier. Ante el nuevo ataque, se volvió a tratar en el Cabildo el proyecto de construcción del fuerte a situarse en el medio de las Reducciones. ${ }^{19}$ Pero, a fines de 1784 el proyectado fuerte seguía sin realizarse y el 27 de noviembre Echagüe elevaba al nuevo virrey, marques de Loreto, el pedido para que se aumentaran 40 plazas de blandengues para llegar al número de 100 solicitando y, además, que se mandara "las milicias de Coronda segregadas antes por el Exmo. Señor antecesor de V.E. y unidas a las de las fronteras de esta capital vuelvan por ahora y hasta promover otra vez el punto para ventilar si subsisten o no iguales motivos...". El 28 de noviembre, Loreto ordenaba que se practicaran ambas cosas, pero aclarando que se realizaran "solo por el tiempo indispensable para aplacar la hostilidad indígena". ${ }^{20}$

Al comenzar la década de 1780, entonces, la situación aparece bastante complicada: la necesidad de mejorar los fuertes estaba signada por la conflictividad entre grupos indígenas y ella desorganizaba todo el dispositivo de defensa fronterizo. Por su parte, el cabildo santafesino debía sostener el funcionamiento de las fuerzas militares, las reducciones y los fuertes chaqueños, mientras al mismo tiempo, debía hacerse cargo de remitir contingentes a la frontera sur pampeana y garantizar también el abastecimiento de sus fuertes. ${ }^{21}$ Efectivamente, en 1781, el cabildo debió autorizar el envío de 20 hombres de la Compañía de Dotación a Melincué y hacerse cargo de la provisión de yerba y tabaco, mientras seguía teniendo a su cargo el pago de los sueldos de la Compañía. ${ }^{22}$ La escasez de fuerzas y el habitual envío de efectivos al sur tornaba fundamental revitalizar a los pueblos para que mantuvieran su función defensiva. ${ }^{23}$

\footnotetext{
${ }^{18}$ Ver nota 10.

${ }^{19}$ ACSF 27 de Marzo de 1781, Tomo XV, XV f53 v a 55 v.

${ }^{20}$ AGN,IX, Guerra y Marina, 8, 16, Expediente formado con motivo de haberse mandado aumentar cuarenta plazas a la cia de blandengues de la frontera de Santa Fe mientras se consideren necesarias y de remitirse algunos pertrechos y municiones para su defensa.

${ }^{21}$ ACSF, 11 de Abril de 1778, Tomo XIV B, XIV f 495 v a f 497.

${ }^{22}$ ACSF, 22 de Enero de 1781, Tomo XV, XV f42 a 45 v.

23 A las escasas fuerzas militares se agrega el problema de la deserción o abandono del servicio como sucedió en el año 1792 cuando el Corregidor de la Reducción de Abipones de San Jerónimo informaba que todos los naturales la habían abandonado cuando se levantó la guardia de Blandengues de la Compañía de Dotación que durante unos 8 años la había guarnecido y cuya dotación rondaba entre 15 y 20 hombres. Sobre este fuerte véase Battcock, 2009.
} 


\section{Los intentos de reorganización a fines de la colonia}

Al comenzar la década de 1790 el funcionamiento de todo el dispositivo defensivo estaba en discusión y comenzaron a plantearse proyectos más integrales mediante el incremento de fuerzas militares y creación de nuevos fuertes. ${ }^{24}$ En la sesión capitular del 2 de junio de 1790, el alguacil proponía elevar la dotación militar de la ciudad de 100 a 200 plazas y dividirlas en dos compañías "a fin de guarnecer con varios fuertes el camino de Santiago [...] y que Córdoba saque el del Tío, hacia afuera. Con ello se facilitará el libre tránsito de dicho camino que es más ventajoso que el que va a Córdoba". Esta propuesta se complementaba con otra: el traslado de los fuertes de San Juan Bautista y San Nicolás y la reparación del de San Francisco Javier con lo que se buscaba cerrar la entrada a los "infieles" del Chaco. A estos tres fuertes se agregaría un cuarto en el paraje de los Sunchales, con lo que se esperaba otorgar un beneficio al comercio ya que se ahorrarían 60 leguas de camino al Perú. ${ }^{25} \mathrm{~A}$ su vez, se dispuso que se destinasen a cada fuerte 10 indios aptos para el servicio ${ }^{26}$ y que en el traslado de los fuertes trabajaran mocobíes de San Pedro y San Francisco Javier. ${ }^{27}$

En 1792 el sargento mayor, Francisco Balcarce, procedió a reorganizar las milicias: habría ahora dos Compañías de Blandengues Provinciales de Caballería (una de la ciudad y otra de Coronda) y 5 Compañías de Milicias Urbanas. ${ }^{28}$ Balcarce un oficial veterano de origen catalán que era para entonces comandante general de la frontera de Buenos Aires - estaba tomando a su cargo la reorganización de los cuerpos de milicias santafesinos y estaba sumando a la Compañía Veterana de Blandengues de Santa Fe dos compañías milicianas adicionales que se habrían de designar como de Blandengues Provinciales. Se trataba de dos fuerzas complementarias pero de distinta naturaleza. Los Blandengues de la Frontera de Buenos Aires fueron transformados en cuerpo veterano en 1784 y la misma decisión se aplicó a la compañía santafesina que ya ostentaba la designación de Compañía de Dotación. Como lo muestran las hojas de servicio de sus oficiales, al menos desde 1787 la compañía era calificada como veterana ${ }^{29}$ y para 1790 los informes de las autoridades virreinales sostenían esa condición:

Es veterana; se compone de un Capitán, un Ayudante Mayor, otro segundo, un Teniente, un Alférez, dos Sargentos, un tambor, cuatro Cabos y noventa y tres soldados, a cuya fuerza se atiende con la gente del país; es de sueldo continuo, satisfecho por el ramo de arbitrios de aquella ciudad. Su

\footnotetext{
${ }^{24}$ Esta reorganización tiene su explicación en los cambios generales realizados en las colonias a mediados del XVIII cuando la Corona comenzó a adoptar una nueva concepción, la "defensa total". Un relato exhaustivo de estas modificaciones se ha desarrollado en Fradkin 2009.

${ }^{25}$ ACSF, 2 de Junio de 1790, Tomo XVI A, XVI f 65 v a 71.

${ }^{26}$ ACSF, 5 de Septiembre de 1792, Tomo XVI A, XVI f $160 \mathrm{v}$ a f 162.

${ }^{27}$ ACSF, 24 de Marzo de 1794, Tomo XVI A, XVI f 255 a 262.

${ }^{28}$ ACSF, 28 de Junio de 1792, Tomo XVI A, XVI f 141 a f 143 y 2 de Julio de 1792, Tomo XVI A, XVI f $143 \mathrm{v}$ a f 145.

29 “Compañía de Blandengues de Santa Fé. Ojas de Servicios. Año 1787”, Archivo General de Simancas (AGS), SGU,LEG,7257,16. C-16; Fol. 1-7.
} 
uniforme: casaca corta azul; vuelta, collarín, solapa, chupa y calzón, encarnados; botón blanco. No hay noticia del año de su formación, pero es verosímil sea desde la fundación de aquella ciudad, que desde los principios ha estado expuesta a la invasión de los indios infieles sus vecinos, en cuya defensa hace su servicio esta compañía; sus individuos se costean su vestuario y tiene obligación de comprar y mantener sus caballos". ${ }^{30}$

La innovación que estaba introduciendo Balcarce era la formación de dos tipos de milicias auxiliares de la Compañía Veterana: los llamados Blandengues Provinciales de Santa Fe y las milicias urbanas de Santa Fe. La distinción es decisiva pues al asignarles a los milicianos Blandengues santafesinos carácter de "Provinciales" se buscaba afirmar su subordinación al mando militar superior y su condición de fuerza auxiliar de los cuerpos veteranos por lo que, no sólo debía operar a escala local, sino de toda la Intendencia.

Estas decisiones apuntaban a darle mayor centralización y coordinación a la política de fronteras pero, aun así, ella seguía dependiendo de la activa colaboración del Cabildo y los recursos humanos y materiales santafesinos no sólo para la defensa de la frontera chaqueña, sino también, de la frontera sur. Esta situación solía enfrentar a la elite santafesina y a las autoridades del Virreinato las cuales en el cuerpo capitular $\mathrm{y}$ en los vecinos los costos de su mantenimiento.

Los intentos reformistas se pusieron de manifiesto en otro aspecto importante que hacía a la relación entre Compañía de Blandengues y elite santafesina: el reclutamiento de su oficialidad. Melchor Echagüe y Andía había ostentado el mando entre 1776 y 1786 y desde entonces continuó como subdelegado de guerra y sargento mayor (y por lo tanto, comandante de las milicias) hasta que en 1792 fue reemplazado por Prudencio de Gastañaduy (Cervera 1908:550). Echagüe y Andía era un miembro de un destacado linaje santafesino que había hecho toda su carrera militar en la compañía de Blandengues de Santa $\mathrm{Fe}^{31}$. En tanto, Gastañaduy era un capitán de Dragones que había iniciado su carrera miliar como guardiamarina en 1775 y que había ascendido en la Marina Real hasta el rango de teniente de navío. ${ }^{32}$ El traspaso de la comandancia de un miembro destacado de la elite local a otro de origen peninsular y reclutado en la burocracia militar imperial suponía un cambio importante que apuntaba a sustraer al cuerpo de Blandengues del control directo de la elite local y expresaba también

\footnotetext{
${ }^{30}$ Antonio Olaguer Feliú, "Virreinato de Buenos Aires. Relación comprensiva del número y clases de todos los Cuerpos veteranos y Milicias de Infantería, Caballería, Dragones y Artillería que hay en la jurisdicción del expresado Virreinato", Buenos Aires, 20 de enero de 170, en Beverina,1992,452.

31 "Compañía de Blandengues de Santa Fé. Ojas de Servicios. Año 1787”, AGS, SGU, LEG, 7257, 16. C-16; Fol. 1-7.

32 "Blandengues de Santa Fé", AGS, SGU,LEG,7258,21. Relaciones con expresión de servicios de oficiales de la Compañía Veterana de Blandengues de Santa Fé. Altas y bajas. C-21; Fol. 1-12.
} 
la compleja transición de un cuerpo miliciano en un cuerpo veterano aunque su financiamiento seguía dependiendo de los recursos locales. ${ }^{33}$

Pero, ¿fue alterada la relación entre la oficialidad y la elite local? Las hojas de servicio de los oficiales, sargentos y cadetes muestran que, en 1787, seis de los siete oficiales de la compañía habían nacido en Santa Fe y uno en la península; en los años siguientes el número total se mantuvo inalterable pero se modificó su composición: sólo tres de los siete oficiales de 1798 eran santafesinos y de ellos uno ostentaba el rango de cadete. ${ }^{34}$ Vale mencionar además, que para la última fecha cinco de los oficiales eran calificados como "nobles" de calidad cuando diez años antes ninguno había sido calificado de tal modo, sino con calidades más modestas, como "distinguida" u "honrada". De alguna manera, la compañía parece haber servido de canal de ascenso a una mejor consideración social.

Como en otros contextos, la elite santafesina desplegó diversas estrategias para congraciarse con Gastañaduy y éste buscó mantener las mejores relaciones con ella. El cabildo solicitó que continuara en el mando y en retribución el comandante de armas pidió que le propusiera un sujeto idóneo para designarlo como sargento mayor de milicias. ${ }^{35}$ Sin embargo, la opción de las autoridades virreinales fue distinta y tres años después era designado un oficial de origen peninsular, Faustino Ansay como ayudante mayor de la compañía de Blandengues con ejercicio del cargo de Sargento Mayor: era un oficial veterano de origen peninsular el que quedaba al mando directo de las milicias. ${ }^{36}$

El mismo acuerdo entre el gobernador y la elite se puede observar en el tratamiento de las reducciones. Hacia 1793 la reorganización de la línea de fuertes y fortines se había concretado y se complementó con una exhaustiva visita realizada por Gastañaduy a las cuatro reducciones (San Pedro, San Javier, San Jerónimo y Cayastá). La visita no se realizaba solamente para tener un conocimiento más puntual de la situación en las reducciones, sino para lograr el repoblamiento de las mismas juntando a la población que se había dispersado por el campo. Comparando las cifras de población brindadas por Gastañaduy con el padrón existente para el año 1785 (Suárez, 2004) se puede ver una clara recomposición en casi todas las misiones: en San Javier se pasó de 274 familias con 1046 integrantes a 366 familias con 1301 personas; en San Pedro, de 111 familias con un total de 589 indígenas a 268 familias con 643 personas. Los

\footnotetext{
${ }^{33}$ Los dilemas de la política defensiva borbónica y sus disímiles resultados regionales han sido analizados por Kuethe, 2005ª y b; Marchena Fernandez 2003.

${ }^{34}$ Estos datos provienen de "Compañía de Blandengues de Santa Fé. Ojas de Servicios. Año 1787", AGS, SGU,LEG,7257,16. C-16; Fol. 1-7; "Blandengues de Santa Fé", AGS, SGU, LEG,7257,12 (1791): Libro de Servicios de los Oficiales, Sargentos y Cadetes. Blandengues de Santa Fé. C-12; Fol. 1-8, Santa Fe, 1/07/1791; "Compañía Veterana de Blandengues de Santa Fe. Ojas de Servicios", AGS, SGU,LEG,7258,7.. C-7; Fol. 1-9, 31 de diciembre de 1798.

${ }^{35}$ Se le propuso una terna integrada por Francisco Antonio Candioti, Manuel Ignacio Diez de Andino y Martín Francisco de Larrechea, es decir, miembros muy destacados de la elite local ACSF: 20 de Julio de 1795, Tomo XVI B, XVI f 309 v a 311.

${ }^{36}$ ACSF, 17 de Agosto de 1798, Tomo XVI B, XVI f 485 v a 487 v.
} 
pueblos -no contemplados en el padrón de 1785- de Cayastá y San Jesús Nazareno de Ispin, creado a 5 leguas al noroeste de San Pedro tenían 60 familias con 167 personas y 511 personas respectivamente. ${ }^{37}$ La única misión que claramente había perdido una parte importante de su población era la de San Jerónimo que había pasado de 679 personas en el padrón de 1785 a 352, 8 años después.

Para 1801 el Cabildo ${ }^{38}$ destacaba la obra realizada por Gastañaduy con la reedificación de los pueblos y fuertes que había permitido el avance de las estancias y poner fin a los ataques de los indios. En el pueblo de San Javier, por ejemplo, la situación había cambiado notoriamente: mientras en 1793 no había atahona, carpintería, ferretería ni animal alguno, ahora contaba con una estancia de 5.000 cabezas y los indios habían vuelto a cumplir tareas como milicianos. Al año siguiente Gastañaduy sugería realizar una entrada al Chaco para asegurar las propiedades del pueblo más fronterizo, San Jerónimo. La expedición militar, según su apreciación, podría contar con "100 hombres de armas de cada uno de los pueblos de San Jerónimo, San Pedro e Ispín, a los que se agregarán 20 soldados con su cabo”. Claramente, el peso relativo de los dos tipos de fuerzas daba una importancia fundamental a los lanceros indígenas. ${ }^{39}$

Cabe preguntarse entonces, ¿cuáles eran las fuerzas disponibles en Santa Fe y que naturaleza tenían? La Compañía Veterana de Blandengues de Santa Fe no llegaba a completar los 100 efectivos estipulados, una dotación se había demostrado como un límite inflexible, aunque desde la década de 1720 repetidamente se propuso que contara con 200 plazas, pero nunca parece haber llegado a tener esa magnitud. Por el contrario, a mediados de siglo no llegaba a 60 y cuando se procedió a convertir a los Blandengues en una fuerza veterana sólo se logró completar una dotación de 100 plazas, con un pico de 104 en 1804 y un piso de 83 al año siguiente. ${ }^{40}$ Conviene registrar que en los años previos a las invasiones inglesas de 1806 y 1807, su fuerza efectiva había sufrido una reducción que rondaba el 15\%. Sin embargo, a pesar de ser una fuerza de magnitud reducida con tendencia decreciente, lograba retener mayor proporción de efectivos que las compañías de Blandengues de Buenos Aires y, sobre todo, que el cuerpo de Montevideo y era la única fuerza veterana de la zona.

Esta dotación era insuficiente, por cierto, para cubrir las necesidades de la serie de fuertes que se había querido implementar. Para 1799 contaba con una Plana Mayor integrada por su Comandante (Gastañaduy); un Ayudante Mayor (Faustino Ansay); 2 Capellanes (Juan Francisco Silva en la ciudad y Fr. Mariano Amaro en el Fuerte de la Virreina); un capitán; un teniente; un alférez; dos sargentos, un tambor y cuatro cabos.

\footnotetext{
${ }^{37}$ AGN,IX, Tribunales, 139, 2. Informe de Gastañaduy, 11 de septiembre de 1793.

38 ACSF,Tomo XVII A, XVII f $13 \mathrm{v}$ a f $16 \mathrm{v}$.

${ }^{39}$ Gastañaduy al Cabildo, 8 de noviembre de 1802, ACSF ,Tomo XVII A, XVII f $120 \mathrm{v}$ a f $121 \mathrm{v}$.

${ }^{40}$ Estos datos provienen de las ACSF (sesiones del 8/08/ 1724, 5/08/1734, 11/01/1778, 30/03/1778, 7/12/1784, 4/04/1789, 2/06/1790, 21/01/ 1793), Archivo General de Simancas, SGU, Leg. 7300, 19 (1799-1802), y Archivo General de la Nación (AGN), Guerra y Marina, IX, Leg. 8, Exp. 16, AGN, Listas de Revista, XIII-9-5-4, XIII-9-5-6, XIII-23-2-4 y XIII-23-2-5 correspondientes a los años 18011804.
} 
Se trataba de una estructura de mando insuficiente y menor que la que disponían las Compañías de Buenos Aires o Montevideo. Sus soldados eran 93 y estaban distribuidos de la siguiente manera: 15 en el fuerte de Almagro, 23 en el fuerte de Feliú, 23 en el fuerte de la Soledad, 8 en el fuerte de la Virreina, 1 en la estancia de San Javier, 2 en la estancia del Quebracho, 4 de guardia en la Cárcel, 1 en las Cajas Reales, 7 enfermos y 9 en la ciudad. ${ }^{41}$

Una dotación tan insuficiente requería del complemento de las milicias. El reglamento virreinal de milicias aprobado en 1801 indicaba que en la ciudad de Santa Fe debía haber un "Escuadrón de Voluntarios de Caballería" con 301 plazas (Beverina 1992:310). Esa dotación nunca fue alcanzada: entre enero de 1804 y agosto de 1810 la Compañía de Milicias Provinciales mantuvo una dotación reducida alcanzando su pico hacia 1805 con 21 efectivos y un mínimo de 15 en 1810. A su vez, existía también una Compañía de Milicias a sueldo que tuvo una dotación más variable entre enero de 1804 y agosto de 1810 llegando a su máximo en febrero y marzo de 1804 (43 efectivos) y su piso en agosto de 1810 (16 efectivos). ${ }^{42}$

Resumiendo: las fuerzas disponibles rondaban los 160 hombres, sin contar con la movilización ocasional de las milicias y, sobre todo, sin contar a los auxiliares indígenas, por lo que es posible suponer que el dispositivo de defensa debía seguir dependiendo en buena medida de las reducciones que seguían en funcionamiento: San Jerónimo, San Pedro, San Javier e Ispin. ${ }^{43}$

Ello permite registrar el tremendo desafío que supuso para Santa Fe la movilización revolucionaria. El 31 de agosto de 1810 se ordenaba disciplinar a 200 Blandengues y armar una nueva "compañía patriótica" de 100 hombres, los cuales habrían de sumarse a la expedición enviada al Paraguay. Para noviembre se informaba la existencia de tres compañías de voluntarios de caballería, y al menos, dos compañías de milicias urbanas, una de "Nobles patriotas Urbanos" con 76 plazas y otra de "pardos libres" (Trelles 1960:70-73). Si a ello se agregan los hombres que pasaron a engrosar la expedición de Ortiz de Ocampo enviada a Córdoba, todo indica que durante el año 1810 se produjo un debilitamiento sustancial del dispositivo de defensa fronterizo y un incremento notable de la movilización. No extraña que en esas condiciones aumentara la conflictividad con los grupos indígenas chaqueños así como, las tensiones entre las autoridades santafesinas y las superiores al punto que aquellas convirtieron la desatención de sus necesidades de defensa en un argumento central para justificar su oposición a la capital en 1815.

\footnotetext{
41 "Extracto de la revista de la Compañía Veterana de Blandengues de la Frontera de Santa Fe realizada por don Rafael Martínez Ministro de la Real Hacienda y Comisario de Guerra de la que es Comandante el Teniente Coronel don Prudencio de Gastañaduy al $1^{\circ}$ de julio de 1799”, AGS, SGU, Leg. 7300, 19.

42 AGN, XIII-9-5-4, XIII-9-5-6; XIII-9-6-1 y XIII-9-6-5.

43 "Razón de las parroquias de esta diócesis de Buenos Aires y curas que actualmente las sirven con inclusión de las doctrinas y reducciones de su pertenencia “, Buenos Aires, 24 de noviembre de 1810, Archivo General de la República Argentina, Periodo de la Independencia. Año 1810, Publicación dirigida por Adolfo P. Carranza, Segunda Serie, Tomo V, Buenos Aires, Kraft, 1896, pp. 120-127.
} 
Entre 1803 y 1813 hay un silencio en las actas del Cabildo sobre la situación de las reducciones pero la evidencia documental para los primeros años revolucionarios muestra que los problemas de abastecimiento ocupaban el primer plano y que la pluralidad de actores indígenas dificultaba a las autoridades santafesinas mantener hacia ellos una estrategia coherente. A la mencionada rivalidad entre abipones y mocovíes se agregaba que, según se informaba en 1793, "los campos estaban llenos de tobas" que se apropiaban de ganado. ${ }^{44}$

\title{
Blandengues y fuerzas indígenas en el período revolucionario
}

Según las memorias del vecino Urbano de Iriondo, hacia 1812 las autoridades santafesinas temían un ataque de la escuadra realista; para enfrentarla el gobierno "hizo venir armados a cuantos indios pudo en número considerable" a los cuales "Se les hizo entender que éramos una misma nación y defendíamos una misma causa contra los españoles". En tales condiciones, a la sala del cabildo asistieron

\begin{abstract}
los indios principales y vecindario de esta ciudad, y fue celebrada esta unión con salva de cañón y repiques, sin que varios vecinos dejasen de ver en este acto la ruina de esta Provincia pues los indios que entonces no eran tan idiotas como después que los dejaron sus Curas, se envalentonaron de tal modo que el cacique D. Manuel Alaiquin se dejó decir que 'si los españoles conquistaron nuestro territorio y nos dominaron sus hijos son sus herederos de estos mismo'. $\mathrm{Al}$ retirarse saquearon por el monte de Noguera una tropa de carretas que iba para Santiago [del Estero]" (Iriondo 1942:29).
\end{abstract}

Aunque se trate de una versión retrospectiva y cargada de prejuicios, sugiere tres aspectos centrales: por un lado, la necesidad imperiosa que tenían las autoridades santafesinas de establecer una alianza con los indios de las reducciones. Por otro, que las dificultades para forjarla eran enormes; por último, que los años transcurridos desde la expulsión de la Compañía de Jesús pueden haber sido decisivos para el desarrollo de nuevas estrategias indígenas.

Los efectos de la movilización de 1810 y la consiguiente desorganización de la defensa fronteriza tuvieron efectos inmediatos en las relaciones inter-étnicas. A mediados de 1813 los indios volvieron a abandonar los pueblos repartiéndose en las estancias rurales e incrementándose los robos de ganado. ${ }^{45}$ Para intentar resolverlo, en noviembre de ese año el Cabildo decidió "la compra de un diezmo de cuatropea para repartir entre los pueblos reducidos “y se les quite el motivo de dispersase por los

\footnotetext{
44 ACSF, 17 de Enero de 1793, Tomo XVI A, XVI f 177 a f 178 v. Tobas y vilelas, aliados a los mocovíes, habían atacado el pueblo abipón de San Fernando que fue abandonado luego del ataque.

45 ACSF, 2 de Agosto de 1813. Actas Recuperadas Caja 1, Acuerdos de 1813, f. 39 - 41.
} 
campos a los robos y asesinatos". ${ }^{46}$ Ese auxilio no logró la reunión de los naturales en sus pueblos y poco después, la política cambió totalmente ordenándose en febrero de 1814 llevar adelante una acción ofensiva con los mismos vecinos víctimas de los ataques, a los que el cabildo y el vecindario auxiliaron con armas y municiones. ${ }^{47}$ De este modo, el debilitamiento de los Blandengues había dejado la defensa casi exclusivamente en manos de los vecinos y, al parecer, roto con las instancias habituales de mediación y negociación.

Esta acción incrementó la hostilidad indígena. Para contenerla, en la sesión del 15 de marzo se acordó invitar a los corregidores de las reducciones a la sala capitular "para tratar con ellos de una pacificación general" ${ }^{48}$ La reunión se llevó a cabo dos días después y en ella participaron los corregidores de la Reducción de San Javier, de San Pedro y de San Jerónimo. El ayuntamiento se comprometió a entregar a la brevedad, ganado vacuno para el abastecimiento de los cuatro pueblos y los corregidores, a su vez, se comprometían a reunir a los indios en sus respectivos pueblos, a controlar el ingreso y salida de indios de cada pueblo para cortar los robos que se habían estado produciendo y a perseguir a los "indios montaraces" por ser considerados los que más daños provocaban y eran más difícil de corregir. Para la persecución de los mismos los corregidores debían utilizar sus propias fuerzas y en caso de ser insuficientes se aclaraba que "este Gobierno los auxiliará con la que se pueda" aunque se advertía que esa ayuda militar "por ahora es inverificable." 49

Es probable que la imposibilidad de entregar el auxilio militar se haya extendido al ganado ya que poco después se renovaron las quejas de los vecinos por los robos ocasionados por los indios. La elite capitular no tenía una política coherente y homogénea sobre las reducciones y poco después se presentó un nuevo plan que proponía la extinción de las reducciones de San Pedro, Ispin, la mayor parte de San Javier, "dejando al de San Jerónimo por su regular conducta". ${ }^{50}$ Llama la atención el giro de alianzas de la elite santafesina que plantea la disolución de los pueblos mocovíes y el sostenimiento de la reducción abipona. En la década de 1780 el administrador Tarragona había señalado que "los mocovies han sido aliados de los españoles en todas las entradas contra ellos [los abipones]" a quienes describía como una nación "altiva y soberbia sin subordinación". ${ }^{51}$ Este cambio de alianzas puede originarse en las relaciones más personales que se habían tejido entre vecinos e indígenas. Según Suarez y Tournay (2003: 521) tanto el gobernador Echagüe como Tarragona, eran partidarios de los mocovíes y denunciaban los ataques abipones que ponían en peligro la seguridad de los primeros pueblos. Y de hecho, en el padrón levantado por Gastañaduy en 1793, había cuatro indios mocovíes del pueblo de San Pedro que llevaban el apellido

\footnotetext{
${ }^{46}$ ACSF, 10 de Noviembre de 1813, Actas Recuperadas Caja 1, Acuerdos de 1813, f. 49 - 50 v.

${ }^{47}$ ACSF, 24 de Febrero de 1814, Actas Recuperadas Caja 1, Acuerdos de 1814, f. 12 v. -13.

${ }^{48}$ ACSF, 15 de Marzo de 1814, Actas Recuperadas Caja 1, Acuerdos de 1814, f. 15 - 16 v.

${ }^{49}$ ACSF, 17 de Marzo de 1814, Actas Recuperadas Caja 1, Acuerdos de 1814, f. 17 - 18 v.

${ }^{50}$ ACSF, 2 de Junio de 1814, Actas Recuperadas Caja 1, Acuerdos de 1814, f. 32 - 32 v.

${ }^{51}$ Informe del administrador de pueblos, Don José Tarragona elevado al virrey en junio del año 1780, en AGN,IX, Justicia, 8, 115.
} 
Tarragona. Durante la gestión de Gastañaduy, primó una visión más estratégica y el gobernador señalaba en su informe de 1793 la necesidad de mantener San Jerónimo por ser "la precisa entrada de los infieles del Chaco, por la parte al poniente". ${ }^{52}$ Además de su lugar estratégico, cabe recordar que los abipones conformaban el mayor número de indios de pelea y alguno de ellos, diestros en el manejo de armas de fuego.

Si bien la medida no parece haberse llevado a cabo, la noticia no hizo más que incrementar la hostilidad indígena que fue aprovechada por Artigas para captarlos como milicias auxiliares. ${ }^{53}$ La situación santafesina hacia 1814 era dramática: todavía sometida a la obediencia de la capital, no recibía desde ella auxilios efectivos; con armamento reducido, los Blandengues "desnudos e insubordinados" y escasez de guardias en la frontera, aumentaban las incursiones de los indios. ${ }^{54}$ Además, en setiembre de 1814 se informaba que el indio Manuelito, corregidor de la reducción de San Javier, se había pasado a los insurgentes artiguistas con 400 indios "acompañado y tal bez aconsejado de su Cura Francisco Europeo Aspiuru con miras de operar ostilm.te contra esta Ciudad [Santa Fe]." ${ }^{55}$ A principios de 1815 los informes señalaban que "la Indiada son miles, q.e a fuerza de armas no se sujetan ni se sujetarán". ${ }^{56}$

En marzo de 1815, el teniente de gobernador, Eustaquio Díaz Vélez, comunicó al Cabildo que "el Jefe de los Orientales ha mandado a su hermano Manuel a unirse con los indios fronterizos para atacar a las tropas del estado de las Provincias Unidas radicadas en la ciudad". ${ }^{57}$ Los primeros aliados de Artigas en territorio santafesino parecen haber sido los indios de la antigua reducción de charrúas de Cayastá, un pueblo que había padecido una larga decadencia desde que, en 1784 y a consecuencia de los constantes ataques de abipones, se decidió su traslado a una región sin aguadas permanentes que dificultaban el cultivo y el pastoreo de ganado. ${ }^{58}$ No es de extrañar que en esas condiciones, la alianza con Artigas haya sido una opción atractiva.

Desde allí, Manuel Artigas, marchó sobre la ciudad de Santa Fe donde entró junto a tres caciques y a Fray Ignacio Yspurga, cura del pueblo de San Javier, mientras el corregidor Manuel con cuatrocientos a quinientos indios permanecía a cuatro leguas. Parecería entonces, que en la primera introducción de las tropas artiguistas en territorio santafesino se buscó y logró, la alianza de los grupos indígenas más perjudicados por el

\footnotetext{
52 Informe de Gastañaduy, 7 de octubre de 1793, en AGN, IX, Tribunales, 139, 2. “Obrado a representación de Cipriano Lenzinas indio charrua del pueblo de la concepción de Cayasta sobre el estado de dicho su pueblo".

${ }^{53}$ Como es sabido José Gervasio Artigas se había convertido hacia 1813 en el líder de la disidencia federal que en la Banda Oriental y todo el litoral se oponía a la política centralista de la dirigencia porteña: véase, por ejemplo, Frega 2008 y Fradkin 2010.

${ }^{54}$ Ignacio Alvarez al Director Supremo, Santa Fe, 12 de marzo de 1814, en Comisión Nacional Archivo Artigas, Archivo Artigas (AA), Tomo XIV, Montevideo, Tarma, 1976, pp. 148-150.

55 AA, E. Díaz Vélez a G. Posadas, Santa Fe, 10 de setiembre de 1814, Tomo XX, pp. 17-18.

56 AA, Francisco Candioti al gobierno, Santa Fe, 20 de enero de 1815, Tomo XX, pp. 128-129.

${ }^{57}$ ACSF, 14 de Marzo de 1815, Actas Recuperadas Caja 2, Acuerdos de 1815, f. 16. - 17. E. Díaz Vélez a J. Viana, Santa Fe 13 de marzo de 1815, en AA, Montevideo, Tarma, 1981, Tomo XX, pp. 237.

${ }^{58}$ AGN,IX, Tribunales, 139, 2. "Obrado a representación de Cipriano Lenzinas indio charrua del pueblo de la Concepción de Cayasta sobre el estado de dicho su pueblo".
} 
Fradkin y Ratto. Reducciones, blandengues y "el enjambre de indios del Chaco"

gobierno: los charrúas y los mocovíes cuyos pueblos corrían el peligro de desaparecer. Estas alianzas se entablaron con la intermediación de las autoridades de las reducciones, curas, corregidores y caciques e incluyeron la tolerancia de los jefes artiguistas hacia las motivaciones y acciones indígenas dado que los indios luego de la partida de Manuel Artigas hacia Paraná se apropiaron de "cuanta hacienda encontraron" (Diario 2008:3132).

En un segundo momento, la alianza de Artigas con los indios chaqueños parece haber incluido también a grupos abipones. A principios de 1816, el caudillo oriental indicaba al cabildo correntino que le asignase un lugar al cacique Benavides para instalarse con sus naturales y familias. ${ }^{59}$ Días después le reclamaba por la falta de apoyo al cacique y reiteraba que esos indios "me serían útiles. Es preciso (como ya tengo prevenido a V.S.) qe a los Indios se los trate con mayor consideración: pues no es dable quando sostenemos ntros derechos excluirlos del qe mas justam.te les corresponde." ${ }^{00}$ Para entonces, Artigas reconocía que sus alianzas con indios chaqueños incluían "además de los Guaicuruses que tenemos reducidos a nuestra sociedad mas de 400 indios Abipones con sus correspondientes familias que he podido atraer con cuatro Caciques por medio del principal Don José Benavides"; para ellos solicitaba útiles de labranza y semillas. ${ }^{61}$

La situación en Santa Fe había empezado a cambiar sustancialmente con el triunfo del movimiento autonomista en marzo de 1816 y la retirada de las tropas directoriales. El gobierno de Mariano Vera, que se extendió entre marzo de 1816 y julio de 1818, reorganizó los Blandengues buscando formar dos compañías que en conjunto apenas superaban los 100 efectivos y adoptando una nueva denominación: Dragones de la Independencia. ${ }^{62} \mathrm{~A}$ su vez, buscó estabilizar las relaciones con los indios mocovíes -los mas cercanos a la ciudad- y convertirlos en aliados. La estrategia parece haber sido exitosa y a fines de agosto de 1816 el corregidor de la reducción de San Javier movilizaba unos 600 indios en auxilio del gobernador Vera (Diario 2008:70).

Pero esta situación no resolvía las tensiones en la frontera chaqueña santafesina ni estabilizaba las relaciones ya que en 1817 y 1818 fueron repetidas las incursiones de diversos grupos indígenas sobre Santa Fe. En tales circunstancias, a principios de 1818 Vera se vio forzado a retirar sus Blandengues de Entre Ríos y destinarlos a la defensa de la ciudad. ${ }^{63}$ No fue suficiente y pocos días después le advertía a Artigas

\footnotetext{
59 AA, José Artigas al cabildo de Corrientes, Purificación, 2 de enero de 1816, Tomo XXIX, 124.

${ }^{60}$ AA, José Artigas al cabildo de Corrientes, Purificación, 31 de enero de 1816, Tomo XXIX, 152-153.

61 AA, José Artigas al Cabildo de Montevideo, Purificación, 22 de junio de 1816, Tomo XXI, 394.

${ }^{62}$ Que esa nueva denominación no tuvo éxito inmediato lo demuestran cabalmente las anotaciones del diario de Andino que en los años siguientes hace referencia a los "Blandengues Dragones" o mucho más frecuentemente a los Blandengues.

63 "Los indios" - -sin identificarse su pertenencia- habían atacado Santo Tomé y el gobernador Vera debió ordenar a los Blandengues que estaban movilizados en territorio entrerriano que regresasen a defender la ciudad. Mariano Vera al Comandante de Paraná José I. Vera, Santa Fe, $1^{\circ}$ de enero de 1818, en Correspondencia oficial, Libro Copiador, 1817-1823, Cuadernos Documentales, Sección Independiente, № 1, Santa Fe, Ediciones del Archivo Histórico de Santa Fe, 1956, p. 39.
} 
que: "Los Indios nos están dando mucho que hacer, pues nos tienen en Armas con sus correrías. Ya nos han reducido al recinto de la ciudad, y aun en ella no se tiene por segura la gente de los arrabales"; para resolver esta situación "y darles un golpe capaz de aquietarlos" le solicitaba que le remitiera 40 o 50 indios "de aquellos en que haya satisfacción de que no se reunirán con los enemigos, los cuales deben ser los que tengan allá a sus Familias, como lo es Benavides con los suios." 64 Resulta claro que, para ese momento la capacidad del gobierno santafesino para forjar alianzas estables con los grupos chaqueños era ínfima y que para la defensa de la ciudad debía apelar a los Blandengues, a las milicias, pero también a grupos indígenas más confiables, aunque ellos respondían a Artigas.

En los meses siguientes los problemas continuaron en una frontera que había retrocedido hasta las inmediaciones de la ciudad, aunque entre los vecinos y las autoridades santafesinas esas incursiones se atribuían a instigaciones de los porteños. ${ }^{65}$ No hemos hallado evidencias que puedan confirmarla pero resulta bastante que junto a la creciente hostilidad entre algunos grupos indígenas y el gobierno de Santa Fe se intensificaron los enfrentamientos entre grupos chaqueños. Para comienzos de marzo de 1818 había un centenar de indios de San Javier en las afueras de la ciudad, armados y al mando de un sargento para disciplinarlos y un oficial indio artiguista de apellido Tixera con 26 hombres se había dirigido a las reducciones. Esta situación que buscaba proteger a Santa Fe era, en cambio, mal vista por los vecinos de Coronda. ${ }^{66}$ Que ello estaba lejos de resolver la situación se advirtió de inmediato. La comisión enviada por Artigas a San Javier para pacificar a los indios no había dado resultados positivos y unos 600 indios habían atacado y saqueado el pueblo de Coronda. Para Vera no había dudas: el cálculo de "tenerlos de nuestro lado" había sido completamente erróneo y "escarmentarlos" era el único remedio "pues no hay otro modo de hacerlos útiles". ${ }^{67}$ Al mismo tiempo, el pueblo abipón de San Jerónimo del Rey fue atacado por tobas aliados a los "montaraces". Ante esto, Vera volvió a solicitar al jefe de las fuerzas orientales en Entre Ríos que le enviase al cacique Benavidez con su gente y algunos soldados para hacer frente a la invasión y dada la intensidad del enfrentamiento tribal que había llevado a que "chicos y grandes, han sido pasados acuchillo". ${ }^{68} \mathrm{Al}$ parecer, los

\footnotetext{
${ }^{64}$ AA, Mariano Vera a José Artigas, Santa Fe, 16 de enero de 1818, Tomo XXXVII, pp. 79-80.

${ }^{65}$ Diario 2008: 120. En marzo de 1818, 600 indios se agolparon sobre el pueblo de Coronda, mataron a 14 vecinos y se llevaron 10 cautivos; Vera extraía del episodio la conclusión de que: "son ciertamente movidos por los Sres. Porteños, pues sus caciques han sido antes llamados a Santiago [del Estero] y desde allí se han dirigido a hostilizar, cuia noticia la comprueba la circunstancia de haber los Indios ultrajado a los Vezinos titulándolos Montoneros. Mariano Vera a José Artigas, Santa Fe, 8 de marzo de 1818, en Correspondencia oficial, Libro Copiador, 1817-1823, Cuadernos Documentales, Sección Independiente, $\mathrm{N}^{\circ}$ 1, Santa Fe, Ediciones del Archivo Histórico de Santa Fe, 1956, p. 50-51.

${ }^{66}$ AA, Juan de Dios Carranza al Coronel Bernabé de San Martín, San Nicolás, 5 de marzo de 1818, Tomo XXXVII, p. 158.

${ }^{67}$ AA, Mariano Vera a José Artigas, Santa Fe, 8 de marzo de 1818, Tomo XXXVII, pp. 161-162.

${ }^{68}$ Mariano Vera al Comandante General de las Fuerzas Orientales en el Entre Ríos Gorgonio Aguiar, Santa Fe, 6 de marzo de 1818, en Correspondencia oficial, Libro Copiador, 1817-1823, Cuadernos Documentales, Sección Independiente, N ${ }^{\circ}$ 1, Santa Fe, Ediciones del Archivo Histórico de Santa Fe,
} 
auxilios de Artigas a Santa Fe se redujeron a enviar unos 200 hombres pero la promesa de "devolución" de los guaycurués no pudo efectivizarla porque los necesitaba para enfrentar la invasión portuguesa..$^{69}$

Estas circunstancias ayudan a comprender el desplazamiento de Vera y el ascenso de Estanislao López al gobierno santafesino a mediados de 1818, cargo que ejerció hasta su muerte en 1838. La construcción de su liderazgo fue inseparable de su ascenso en el cuerpo de Blandengues de la Frontera de Santa Fe y del lugar que esta fuerza adquirió en la sociedad santafesina ${ }^{70}$ así como, la cronología de ese ascenso expresa con claridad los vaivenes de la situación santafesina: López asciende cuando Santa Fe inició su primer movimiento autonomista aliado a los Pueblos Libres en 1815; luego intervino activamente en el levantamiento de marzo de 1816 que independizó a la provincia de la capital y se hizo del gobierno directo en 1818, momento en que el enfrentamiento con el gobierno directorial entraba en su fase decisiva y cuando el gobierno de Vera se mostraba completamente imposibilitado de estabilizar la situación fronteriza.

Como hemos analizado en otra ocasión, los movimientos de 1816 y 1818 expresaron cambios en las bases sociales y regionales del poder santafesino y demostraron el papel decisivo de los Blandengues. López pudo hacerse y mantenerse en el poder con su apoyo, el de las milicias de la ciudad y del partido norteño de Rincón, pero también de las fuerzas auxiliares indígenas que lograba movilizar desde las reducciones. Su afirmación en el poder supuso un cambio decisivo en los grupos indígenas hasta entonces aliados a Artigas y que fueron quedando dentro del ámbito de influencia política de López (Fradkin y Ratto 2008). Ese papel de los Blandengues no devenía sólo de la ausencia de otra fuerza armada que pudiera rivalizar con ellos, sino también, de la legitimidad social adquirida a través de una larga trayectoria y en las posibilidades que tenían sus jefes de tramar alianzas con los grupos indígenas de las reducciones las que evidenciaron toda su potencialidad cuando se convirtieron en actores políticos decisivos.

Lo que parece bastante claro es que López decidió su alianza con los abipones y con la colaboración militar de ellos logró vencer la resistencia de los mocovíes volviendo a reducirlos en los pueblos de San Javier, San Pedro y Santa Rosa de los Calchines (Green 2005). La correspondencia de López de esos años muestra la utilización de

1956, p. 50.

${ }^{69}$ AA, José Artigas a Mariano Vera, Purificación, 3 de abril de 1818, Tomo XXXVII, pp. 200-201.

${ }^{70}$ Desde 1804 hasta 1810 López prestó servicios en las compañías de milicias provinciales y aunque la mayor parte del tiempo estuvo destinado a la ciudad de Santa Fe en 1804 prestó servicio en el fuerte del Socorro y en 1807 en el fuerte Almagro. Después de servir en la expedición que comandó Manuel Belgrano al Paraguay, en agosto de 1812 fue designado alférez de la $2^{\text {a }}$ Compañía de Blandengues, en 1815 Teniente $2^{\circ}$ de la $1^{\text {a }}$ Compañía, en abril de 1816 ascendido al grado de capitán y en setiembre a Teniente Coronel y Comandante de Armas de Santa Fe y, a la vez, Comandante del Escuadrón $1^{\circ}$ de Dragones de la Independencia. Para 1818 se transformó en Gobernador Interino y luego en Gobernador Propietario de Santa Fe: PEL, Vol. I, 1804-1819, pp. 7, 11, 15, 18 y 24-25. Para la trayectoria de López véase Tedeschi, 1999 y 2000; Goldman y Tedeschi, 1998. 
un repetido recurso: movilizar grupos indígenas a través de algunos líderes indígenas así como, precisas instrucciones a sus oficiales para no que no ahorraran esfuerzos para garantizarla, así como también, evidencia que esa movilización estaba sujeta a múltiples contingencias y renegociaciones. ${ }^{71}$ Para setiembre de 1818 las autoridades fronterizas de Buenos Aires advertían del peligro que se cernía: “q.e los Santafesinos en unión con los indios Guaycuruses se preparan arobar esta Camp.a e impedir el Tráfico a las Prov.s interiores". ${ }^{72}$ De este modo, en sus incursiones en territorio bonaerense durante 1820 contaron con activa cooperación indígena. ${ }^{73}$

Sabido es que entre las tropas federales que vencieron al Directorio en la batalla de cepeda el $1^{\circ}$ de febrero de 1820 , las santafesinas contaban con contingentes de indios chaqueños. Que no se trataba de una cooperación automática lo demuestran las órdenes que en agosto de ese año López impartía a Manuel Reyes:

“convide a los indios para pelear contra los porteños; todos los que quieran ... cuidando Ud. de halagarlos con palabras amistosas y que los entusiasmen, pues entrando al territorio porteño llevarán cuanto ganado puedan; que se conviden unos a otros, y Ud. cuide de avisarme lo que resulte, porque si se ofrece Ud. debe caminar con ellos. Esto mismo, también, hágales entender para que tengan más confianza y vengan más contentos. En esto debe Ud. esforzarse todo lo posible y no perdonar medio para conseguirlo". ${ }^{74}$

Resulta claro, como se ha estudiado para otros espacios y momentos, que la cooperación militar indígena requería promesas de compensación y sistemáticos esfuerzos de seducción y creación de una confianza personalizada. Esas compensaciones, con todo, no podían reducirse a la promesa de botín, sino que suponían la necesidad de movilizar recursos y disponer de comisionados - como Nicolás Alzogaray- encargados de reunir el "auxilio de víveres para los indios". ${ }^{75}$ Las compensaciones, además, debían

\footnotetext{
${ }^{71}$ Así, por ejemplo, a principios de 1819 instruía al comandante de armas para que envíe al Sauce al indio Félix "con algunos de los que los siguen", que lo proveyera de vicios y que si se negaba se envíe a Pedro el Zurdo No 137. López al Comandante de Armas Francisco de Echagüe, Cuartel General, 25 de febrero de 1819, p. 104: Papeles...,

${ }^{72}$ Francisco Pico a Matías de Irigoyen, Guardia de Luján, 22 de setiembre de 1818, en AA, Montevideo, Tarma, 2009, Tomo XXXVII, p. 294 y Rafael Hortiguera a Matías de Irigoyen, San Nicolás, 23 de setiembre de 1818, en AA, Montevideo, Tarma, 2009, Tomo XXXVII, p. 299.

${ }^{73}$ La presentación que de su comienzo hizo Bartolomé Mitre no tiene desperdicio: “A las ocho y media de la mañana se levantó una bandera colorada en el centro del ejército federal. A esa señal, se oyeron los clarines de los Dragones de Santa Fe, los timbales de los guaraníes de Misiones y las bocinas de los indios del Chaco, sonando la carga de los montoneros, en medio de gritos salvajes que atronaban el aire", (Mitre 1950: 591).

${ }^{74}$ Papeles... , Vol. II, 1820-1822, 1977, № 219: Gobernador López al Tte. Manuel A. Reyes, cuartel general, 3 de agosto de 1820, p. 25.

${ }^{75}$ Papeles... Vol. II, 1820-1822, 1977, № 236. Gobernador López al Comandante de Armas José R. Méndez, San Lorenzo, 27 de agosto de 1820, p. 35-36.
} 
discriminar favorablemente a algunos jefes indígenas y muchas veces tenían que ser efectuadas realizadas por el propio López: así, por ejemplo, al indio Mateo de San Javier le regaló 100 cabezas al tiempo que "le he recomendado mucho que evite que no nos hagan daño los muchachos. Este es medio caporal, y quizás hace algo, si no es el peor. Ud. recomiende lo mismo y regálele dos frascos de aguardiente, en fin, lo que Ud. pueda en vicios, que el fin es que vayan agradecidos para si se ofrece otra." ${ }^{" 76}$ Aún así, ello no garantizaba la paz completa en la frontera y al mes siguiente López se veía forzado a movilizar a la $4^{\text {a }}$ compañía de Dragones para auxiliar al partido de Rincón y escarmentar a los indios que lo atacaron. ${ }^{77}$

Una vez consolidado en el poder una prioridad del gobierno de López fue estabilizar la situación fronteriza. Para 1822 recibía informes que los abipones habían invadido Goya y Esquina en territorio correntino y estaban refugiados en San Javier por los ataques que sufrían de los tobas. ${ }^{78}$ Ello lo inclinó a proponer una expedición conjunta de Corrientes, Santiago, Entre Ríos, Córdoba y Santa Fe contra "los indios del norte". ${ }^{79}$ Pero cada provincia tenía sus propias estrategias y buscaba tener sus propios indios aliados. Corrientes había firmado un tratado con los abipones y, como se ha visto al comienzo de este trabajo, López desconfiaba de que lo cumplieran pues como le decía al gobernador de esa provincia "han tomado el medio término de hacer paces aparentes con V.S., ya para el logro de sus chinas, ya para tener donde refugiarse". ${ }^{80}$ Aún así, para 1825 López logró un acuerdo con los abipones que quedaban en la reducción de San Jerónimo tras su destrucción en 1818 por los "montaraces" y los trasladó hacia la nueva reducción de San Jerónimo del Sauce a través de la negociación con el cacique abipón Patricio Ríos. Allí se conformó un cuerpo de lanceros y durante su gobierno contó con tres cuerpos de lanceros: el de El Sauce, el de San Jerónimo y el de San Javier (Tarragó 2006:65-66).

\section{Conclusiones}

La experiencia defensiva santafesina aparece hilvanada en torno a los Blandengues y las reducciones indígenas. Como se ha planteado a lo largo del trabajo y en cada etapa analizada, las fuerzas de blandengues desde su creación hasta el ascenso de López al poder habían sido centrales en la defensa fronteriza. Sin embargo, la exigüidad de efectivos tornaba imprescindible contar con otra fuerza que colaborara en

\footnotetext{
${ }^{76}$ Papeles... Vol. II, 1820-1822, 1977, No 248. Gobernador López al Comandante de Armas José R. Méndez, s/d, 13 de setiembre de 1820, p.44-45.

${ }^{77}$ Papeles... Vol. II, 1820-1822, 1977, № 251. E. López al comandante de armas José R. Méndez, Rosario, 13 de octubre de 1820, p. 54.

${ }^{78}$ Papeles... Vol. II, 1820-1822, 1977, № 257. López al gobernador de Entre Ríos Lucio Mansilla, Santa Fe 18 de abril de 1822, p. 130.

${ }^{79}$ Papeles... Vol. II, 1820-1822, 1977, № 358. López al gobernador de Córdoba Juan B. Bustos, Santa Fe, 19 de abril de de 1822, p. 131.

${ }^{80}$ Papeles... Vol. II, 1820-1822, 1977, № 371. López al gobernador de Corrientes Juan J. Blanco, Santa Fe, 25 de junio de 1822, p. 143-145.
} 
la tarea. En ese contexto, se entiende la constante insistencia de la elite santafesina por revitalizar las reducciones indígenas.

Además, un problema recurrente para sostener un eficaz sistema defensivo se centraba en la forma de financiamiento del mismo. Aunque es un tema que amerita una investigación más detallada, los datos que hemos podido obtener hasta el momento, muestran los dilemas que enfrentaba el gobierno santafesino para contar con los recursos necesarios para garantizar el pago de salarios militares y el mantenimiento de las misiones: ¿debían ser girados desde Buenos Aires, cabecera de la Intendencia o debían ser sostenidos por recursos propios del Cabildo?

El éxito de López para estabilizar la situación santafesina hasta 1838 parece explicarse por su alianza con Buenos Aires que le aseguró a Santa Fe la provisión sistemática de recursos financieros; gracias a ellos pudo afrontar sus problemas fiscales y sus gastos de defensa fronteriza, de un modo que nunca habían logrado las autoridades santafesinas de la época colonial o revolucionaria (Chiaramonte, Cussianovich y Tedeschi 1993). Pero también, por las fuerzas que logró consolidar: las compañías de Dragones-Blandengues, las milicias - tanto rurales como de pardos cívicos que guarnecían la ciudad - y los cuerpos de lanceros indígenas que podían suministrar las reducciones. Era, así, una solución de neta matriz colonial adaptada a las condiciones que había creado la era revolucionaria.

Para concluir, los blandengues santafesinos ocuparon entonces, un lugar relevante en la construcción de esa solución. Su trayectoria ilustra las transformaciones de una Compañía de Dotación de naturaleza imprecisa (pero de servicio continuo y a sueldo, sostenida por el cabildo y con una oficialidad designada por autoridades locales) en una Compañía Veterana de Caballería (también de servicio continuo, a sueldo, sostenida por el cabildo pero con oficiales designados por la Corona) a la cual habrían de agregarse dos compañías milicianas. Prefiguraron y anticiparon la transformación de fuerzas milicianas en veteranas y las formas híbridas que podían generarse en ese proceso. Para operar esa transformación no sólo debía modificarse el status legal de las tropas sino también su financiamiento y quién tendría a su cargo la selección de sus oficiales. La solución implementada no podía ser más sugestiva: los costos fueron afrontados por la implantación del llamado ramo de arbitrios de la ciudad. Se esperaba, de este modo, conformar una fuerza veterana de caballería sujeta al comando de autoridades militares superiores pero sostenida en base a la contribución y la colaboración local. Allí residía el punto de fricción más recurrente y la posibilidad de la elite local para convertirla en parte de su esquema de poder. Dado que el resto de las fuerzas veteranas estaban concentradas en Buenos Aires, Montevideo, Colonia y Maldonado, en la mayor parte de las zonas rurales los Blandengues eran las únicas fuerzas veteranas existentes y, por tanto, entre ellos debían escogerse a los veteranos que debían entrenar y disciplinar a las milicias. La experiencia de la Compañía de Blandengues de Santa Fe encontró límites que infranqueables y nunca pasó del nivel de compañía, a diferencia de lo que sucedió en Buenos Aires o la Banda Oriental. Pero era una dotación veterana permanente, a diferencia de lo que sucedió en Corrientes, 
Entre Ríos, Asunción o las Misiones, y no formaba parte efectiva del Cuerpo de Blandengues de la Frontera de Buenos Aires y tenía una laxa, intermitente y mediada subordinación a su Comandancia. Con la revolución las autoridades santafesinas debieron reorganizarlas y hacia 1816 contaban con dos y luego, con cuatro compañías permanentes y les cambiaron la denominación por la de Dragones de la Independencia. ${ }^{81}$

Por su parte, si la utilización de lanceros indios en la defensa fronteriza era una práctica corriente en otros espacios, la experiencia santafesina tuvo sus particularidades. En primer lugar, los asentamientos reduccionales del norte habían intentado terminar con los enfrentamientos tribales que oponían a abipones y mocovíes. Sin embargo, esa estrategia no había dado resultados exitosos y el conflicto no sólo se mantuvo sino que ocasionalmente incorporaba a otros grupos chaqueños no reducidos como tobas y montaraces. En segundo lugar, -y esto deberá ser profundizado en próximos trabajoslos gobiernos y los vecinos santafesinos parecen haber tejido alianzas con algunos de estos grupos y, en ese sentido, los cambios en el liderazgo político habrían llevado a cambios más drásticos en la política indígena. En ese sentido, es muy sugestivo que el cacique charrúa Lencinas, del pueblo de Cayastá, decidiera presentar una denuncia sobre el estado de su pueblo ante el protector de naturales de Buenos Aires en septiembre de 1790 porque "el que hace de protector en la ciudad de Santa Fe es cuñado del mismo Dn Melchor (Echagüe)" de quien aseguraba que "el espíritu de aquel comandante de armas no ha sido ni es otro que arruinar el pueblo de Cayasta". ${ }^{82}$

¿Logró el largo gobierno de López resolver ese faccionalismo? Por el momento no podemos responder el interrogante pero lo que sí parece claro es que pudo consolidar una estructura defensiva en la frontera en la cual los lanceros del Sauce y de San Pedro tuvieron un rol fundamental que, además, se mantuvo por largo tiempo. Así, en 1864, en ocasión de la discusión del presupuesto del Ministerio de Guerra y Marina en la Cámara de Senadores, el ministro Gelly y Obes solicitaba un aumento en los sueldos de los lanceros de San Pedro y del Sauce que debían ser considerados "propiamente tropas de línea al servicio de la frontera que se ha establecido como 90 leguas mas afuera de la línea que existía anteriormente” (Ratto 2011).

\section{Referencias bibliografíca}

Alemano, María Eugenia y Carlón, Florencia. 2009. "Prácticas defensivas, conflictos y autoridades en la frontera bonaerense. Los pagos de Magdalena y Pergamino (17521780)", en Anuario del Instituto de Historia Argentina. La Plata, No 9, 15-42.

Areces, Nidia (comp.). 1999. Poder y sociedad. Santa Fe la Vieja, 1573-1660, Rosario, Prohistoria.

2002. "Milicias y faccionalismo en Santa Fe, 1660-1730", en Revista de Indias, Vol. LXII, $N^{\circ} 226$, 585-614.

${ }^{81}$ ACSF, 29 de marzo de 1815 Actas Recuperadas Caja 2, Acuerdos de 1815, f. 22 - 22v y del 5 de marzo de 1816, Tomo XVII B, XVII f 575 y v

${ }^{82}$ AGN,IX, Tribunales, leg 139, exp. 2. "Obrado a representación de Cipriano Lenzinas indio charrua del pueblo de la concepción de Cayasta sobre el estado de dicho su pueblo". 
Barriera, Darío G. 2006. Conquista y colonización hispánica. Santa Fe la Vieja (1573-1660) y Economía y sociedad (siglos XVI a XVIII), Tomo III, en Darío G. Barriera (Dir.), Nueva Historia de Santa Fe, Tomo II, Rosario, Prohistoria/ La Capital.

Battcock, Clementina, Gotta, Claudia y Manavella, Analía. 2004. "Frontera y poder: milicias y misiones en la jurisdicción de Santa Fe de la Vera Cruz, 1700-1780”, en Cuicuilco, Vol. $11, N^{\circ} 30,1-22$.

2009. "La frontera en tiempo de reformas. El fuerte de Melincué: punto neurálgico en el sur santafesino”, en Estudios de Historia Novoshispana, No 41, 105-131

Beverina, Juan. 1992. El Virreinato de las Provincias del Río de la Plata. Su Organización Militar, Buenos Aires, Círculo Militar, Biblioteca del Oficial.

Chiaramonte, José C., Cussianovich, Guillermo y Tedeschi, Sonia. 1993. "Finanzas públicas y política interprovincial: Santa Fe y su dependencia de Buenos Aires en tiempos de Estanislao López", en Boletín Ravignani, N 8, pp. 77-116.

Cervera, Manuel. 1908. Historia de la Ciudad y Provincia de Santa Fe, 1573-1853, Tomo I, Santa Fe, Librería e Imprenta la Unión.

De la Serna, Juan Manuel. 2005. "Integración e identidad, pardos y morenos en las milicias y cuerpos de lanceros de Veracruz en el siglo XVIII", en Ortiz Escamilla, Juan (coord.), Fuerzas militares en Iberoamérica, siglos XVIII y XIX, México, El Colegio de México/ El Colegio de Michoacán/Universidad Veracruzana, 61-74

Diario de Don Manuel Ignacio Diez de Andino. Crónica santafesina, 1815-1822. 2008. Santa Fe, Universidad Nacional del Litoral.

Djenderedjian, Julio. 2001. "Del saqueo corsario al regalo administrado. Circulación de bienes y ejercicio de la autoridad entre los abipones del Chaco oriental a lo largo del siglo XVIII", en Folia histórica del Nordeste, № 15, pp.175-195;

Fradkin, Raúl O. 2009. "Tradiciones militares coloniales. El Río de la Plata antes de la revolución”, Heins, Flavio M., Experiencias nacionais, temas transversais subsidios para uma historia comparada da America Latina, Sao Leopoldo, Oikos.

2010. "La revolución en los pueblos del litoral rioplatense", en Estudos Ibero-Americanos, Vol. 36, $\mathrm{N}^{\circ}$ 2, pp. 242-265

y Garavaglia, Juan C. 2009. La Argentina colonial. El Río de la Plata entre los siglos XVI y XIX, Buenos Aires, Siglo XXI, pp. 87-110.

y Ratto, Silvia. 2008. "Territorios en disputa. Liderazgos locales en la frontera entre Buenos Aires y Santa Fe (1815-1820)", en Gelman, Jorge y Raúl Fradkin (comps.) Desafíos al Orden. Política y sociedades rurales durante la Revolución de Independencia, Prohistoria ediciones, Rosario, pp. 37-60

Frega, Ana. 2008. “Los 'infelices' y el carácter popular de la revolución artiguista”, en Fradkin, Raúl O. (comp.), ¿Y el pueblo dónde está? Contribuciones para una historia popular de la revolución de independencia en el Río de la Plata, Buenos Aires, Prometeo Libros, pp.151-176

Giudicelli, Christophe. 2009. “'Indios amigos' y movilización colonial en las fronteras de la Monarquía católica (siglos XVI-XVII), en Ruiz Ibañez, José Javier (coord.), Las milicias del rey de España. Sociedad, política e identidad en las Monarquías Ibéricas, MadridMéxico, Red Columnaria- FCE, pp. 349-377.

Goldman, Noemí y Tedeschi, Sonia. 1998 "Los tejidos formales del poder. Caudillos en el interior y el litoral rioplatense durante la primera mitad del siglo XIX", en Goldman, Noemí y Salvatore, Ricardo (comps.), Caudillismos rioplatenses. Nuevas miradas a un 
viejo problema, Buenos .Aires, EUDEBA, pp. 135-157.

Green, Aldo. 2005. “El escuadrón de lanceros del Sauce. Una aproximación a las transformaciones operadas en una sociedad india durante la $19^{\circ}$ centuria", ponencia en el IV Congreso de Historia de los pueblos de la provincia de Santa Fe.

Iriondo, Urbano de. 1942. Apuntes para la historia de la Provincia de Santa Fe, Santa Fe, Junta Provincial de Estudios Históricos de Santa Fe.

Juarez Martínez, Abel. 2005. "Las milicias de lanceros pardos en la región sotaventina durante los últimos años de la colonia”, en Ortiz Escamilla, Juan (coord.), Fuerzas militares en Iberoamérica, siglos XVIII y XIX, México, El Colegio de México/El Colegio de Michoacán/Universidad Veracruzana, pp. 75-91.

Kuethe, Allan. 2005. "Las milicias disciplinadas en América", en Marchena Fernández, Juan y Kuethe, Allan (eds.), Soldados del Rey. El Ejército Borbónico en América Colonial en vísperas de la Independencia, Castellón, Ed. Universitat Jaume I, pp. 101-126.

Langer, Eric. 1998. "Liberal policy and frontier missions: Bolivia and Argentina compared", en Andes No. 9. Salta, pp. 197-214

Lucaioli, Carina. 2010. "Los espacios de frontera en el chaco desde la conquista hasta mediados del siglo XVIII", en Lucaioli, C y L. Nacuzzi, Fronteras. Espacios de interacción en las tierras bajas del sur de América. Buenos Aires, Sociedad Argentina de Antropología. 2011. Abipones en la frontera del Chaco. Una etnografía histórica sobre el siglo XVIII, Buenos Aires, Sociedad Argentina de Antropología.

Marchena Fernández, Juan. 1992. Ejército y milicias en el mundo colonial americano, Madrid, MAPFRE.

2003. "La expresión de la guerra. El poder colonial, el ejército y la crisis del régimen colonial”, en Historia de América Andina, Quito, Universidad Andina Simón Bolívar, Vol. 4, pp. 79-128.

Marfany, Roberto. 1933. "El cuerpo de Blandengues de la Frontera de Buenos Aires (17521810)". Humanidades. La Plata. Tomo XXIII, pp. 313-374;

Mayo, Carlos y Latrubesse, Amalia. 1993. Terratenientes, soldados y cautivos: la frontera 1736-1815, Mar del Plata, Universidad Nacional de Mar del Plata.

Mitre, Bartolomé. 1950. Historia de Belgrano y de la Independencia Argentina, Buenos Aires, Anaconda.

Paz, Carlos. 2005. "El nudo gordiano de las políticas indígenas de los grupos chaqueños. Misiones, misioneros y guerras en la génesis de una sociedad de jefatura, segunda mitad del siglo XVIII, Revista Historia Unisinos 9 (1), pp. 35-48.

. 2009. "La modernidad de los bárbaros. Los abipones de San Jerónimo del Rey y sus relaciones sociales con las fronteras santafesinas del Chaco", en História Unisinos, Vol. 13, No 3, pp. 253-264.

Ratto, Silvia. 2008. "Los indios y la revolución en el Río de la Plata. El proceso independentista entre los indígenas soberanos de Pampa y Chaco", en Bragoni, Beatriz y Mata, Sara (compiladoras), Entre la Colonia y la República: Insurgencias, rebeliones y cultura política en América del Sur, Buenos Aires, Prometeo Libros, pp.143-168.

. 2011. "Estado y cuestión indígena en las fronteras de Chaco y la Pampa (1862 1880)", en Revista de Ciencias Sociales, No 20, pp. $7=27$.

Santamaría, Daniel. 1994. "Las relaciones económicas entre tobas y españoles en el Chaco occidental, siglo XVIII”, en Andes 6, Salta, pp. 273-300.

Saeger, James. 2000. The chaco mission frontier. The guaycuruan experience. The University 
of Arizona Press.

Suarez, Teresa y Tournay, María L. 2003. "Poblaciones, vecinos y fronteras rioplatenses. Santa Fe a fines del siglo XVIII, en Anuario de Estudios Americanos, Tomo LX, No 2, pp. 521-555.

2004. "Formaciones familiares de grupos étnicos del Chaco Austral: gentiles y reducidos en pueblos de la jurisdicción del Cabildo santafesino, fines del siglo XVIII" en Suarez T. y Areces N. (Comps.) Estudios históricos regionales en el espacio rioplatense. De la colonia a mediados del siglo XIX, Santa Fe, Universidad Nacional del Litoral, pp. 69-85.

Tarragó, Griselda. 2006. De la autonomía a la integración. Santa Fe entre 1820 y 1853, en Nueva Historia de Santa Fe, Vol. 5, Rosario, Prohistoria Ediciones - La Capital, pp. 6566

Tedeschi, Sonia. 1999. "López", en Jorge Lafforgue (ed.), Historia de caudillos argentinos, Buenos Aires, Alfaguara, pp. 199-234

2000. "Caudillo e instituciones en el Río de la Plata. El caso de Santa Fe entre 1819 y 1838 ”, ponencia presentada a las Primeras Jornadas de Historia Regional Comparada, Porto Alegre.

Teruel, Ana. 1994. "Zenta y San Ignacio de Los Tobas. El trabajo en dos misiones del Chaco Occidental a fines de la colonia", en Anuario IEHS, No 9, Tandil, pp. 227-254.

Trelles, Manuel. 1960. Índice del Archivo del Gobierno de Buenos Aires correspondiente al año de 1810, Buenos Aires, La Tribuna.

Vitar, Beatriz. 1997. Guerra y misiones en la frontera chaqueña del Tucumán (1700-1767) Madrid, CSIC.

Weber, David. 2007. Bárbaros. Los españoles y sus salvajes en la era de la Ilustración, Barcelona, Crítica. 